\title{
The undergraduate experience of the transition of the obstetrics and gynaecology programme to blended learning in response to the COVID-19 pandemic
}

Emma H Tuthill ( $\nabla$ tuthillemma@gmail.com )

University College Dublin School of Medicine https://orcid.org/0000-0002-0998-4590

Mairead M Kennelly

University College Dublin

Laura Bowes

University College Dublin

Eimer G O'Malley

University College Dublin

Chris Fitzpatrick

University College Dublin

Michael J Turner

University College Dublin

\section{Research Article}

Keywords:

Posted Date: February 22nd, 2022

DOI: https://doi.org/10.21203/rs.3.rs-956340/v1

License: (c) (i) This work is licensed under a Creative Commons Attribution 4.0 International License.

Read Full License 


\section{Abstract}

Background: The Covid 19 pandemic radically changed our lives worldwide in 2020 . Control of the pandemic required public health interventions which included social distancing and the minimising social gatherings. The implementation of these measures resulted in major changes in the delivery of healthcare education.

Aim: This observational study reports on the undergraduate experience of the transition of the obstetrics and gynaecology programme from a traditional face-to-face approach to a blended learning programme (BLP) in response to the COVID-19 pandemic.

Methods: Changes to the undergraduate Obstetrics and Gynaecology programme in response to the pandemic are described. These changes were implemented with no additional funding or resources. On completion of the module, students voluntarily completed an anonymous survey on their experience of the BLP.

Results: Of the 80 students who completed the module, $81 \%$ responded. Overall satisfaction with the module was high with median scores for all online and clinical components of the module ranging from 8 - 10. The students expressed high levels of satisfaction with the support they received from their teachers, hospital staff and patients.

Conclusions: To our knowledge, this paper is the first to describe the transition of the entire undergraduate module in Obstetrics and Gynaecology to a BLP in response to the COVID-19 pandemic. The overall satisfaction scores submitted anonymously were high. Whether this will be maintained post pandemic remains unknown but the positive response to the BLP provides direction as to what elements of the revised programme may be worth developing further in the future.

\section{Introduction}

The novel coronavirus (COVID-19), caused by the severe acute respiratory syndrome coronavirus 2 (SARSCoV-2) is a highly contagious viral illness. It was first reported in Wuhan, China in December 2019 and by March 2020 the World Health Organisation declared the outbreak as pandemic.[1] The response to the pandemic has led to unforeseen and major changes globally, not least in healthcare and education.

In the absence of a vaccine, control of the pandemic required public health interventions including social distancing, cough etiquette, personal sanitising, mask-wearing, personal protective equipment and the minimisation social gatherings. The implementation of these measures has resulted in major changes in how healthcare education is delivered. University campuses went into lockdown and educational content has been delivered remotely. Additional challenges are presented in health professionals education degrees where students traditionally attended healthcare facilities to avail of opportunities to learn within the clinical environment. 
The hospital is one of the largest women's hospitals in Europe and accepts medical students from all three Dublin medical schools, including UCD School of Medicine. [2] Until 2020, the undergraduate teaching programme was traditional with daily clinical assignments in the wards, clinics, theatres and delivery suites and students rotated between the Hospital and the nearby National Maternity Hospital. Academic teaching involved face-to- face meetings with clinicians for lectures and tutorials.

The aim of this study was to describe the transition to the undergraduate teaching programme that we implemented in obstetrics and gynaecology and to report on our survey of the students' experience.

\section{Methods}

In response to the pandemic in 2020, the Obstetrics and Gynaecology module was adapted to comply with national guidance set out by the Health Services Executive (HSE) and the hospital to protect patients, students and staff. The programme transitioned to a blended learning approach. The impetus to transition to a blended learning programme was due to suspension of clinical placements initially and the requirement to socially distance and avoid gatherings when clinical placement resumed. Students attended a single maternity unit for the duration of the module rather that rotating between other maternity units. Four groups of twenty students attended the Coombe hospital every 4 weeks from September - December 2020. These students were divided into two mutually exclusive groups of ten. The aim of this approach was to reduce the risk of transmission of COVID-19, limit contacts, facilitate adequate social distancing on site and because clinical opportunities available to students were limited due to supervision requirements imposed by the hospital. Students therefore attended the hospital for two days per week and engaged in online learning from home three days per week.

Within the hospital, students attended antenatal, gynaecology and hysteroscopy clinics, baby clinics, wards and the labour ward. The hospital enforced strict supervision guidance and students were required to be accompanied at all times by a staff or faculty member. The requirement for this level of supervision meant that access to certain areas was restricted, including theatre. University guidance was also adhered to with regard to contact tracing. Students were required to comply with strict hand hygiene and wear a mask, visor, apron and gloves during patient encounters.

Moving a large portion of teaching to a virtual platform was a challenge and required a collaborative approach from teachers and learners. Learning materials were available to students from Brightspace, their learning management system (LMS) platform. Asynchronous lectures were made available to students. In clinical areas where student access was limited or restricted such as labour ward and theatre, freely available video resources were posted within the LMS and many were embedded within case vignettes to put them in a clinical context. These resources were reviewed by senior teaching faculty prior to inclusion to ensure the most appropriate resources were chosen. Students also had access to podcasts and formative multiple choice questions.

One of the difficulties we had with online content was organising it in a way that did not overwhelm students. We did this by filing lectures within categories - antenatal, gynaecology and neonatology and 
subcategories within those. The extraneous cognitive load was reduced for students by the development of study guides for students for each of their four weeks of placement, so that for any given day a student could review a suggested plan for learning. Asynchronous lectures were also ordered in a way that was building on prior knowledge and other complimentary resources including videos, case studies, podcasts and MCQs were embedded.

Students engaged in tutorials throughout the module. This included tutorials occurring in the hospital classroom which students could join virtually through the LMS. There were approximately $6-8$ tutorials per week. One of the challenges in doing this was obtaining the necessary hardware to do so. We did not received any additional financial resources and IT equipment was in short supply given worldwide demand. We obtained a microphone and all students were able to see presentation slides shared by the lecturer and hear the presentation through a microphone worn by the speaker. A new webcam was available to groups 3 and 4 in addition which allowed them to view the tutorial room. The clinical tutor also facilitated small group online role-play tutorials for students at home.

Students were traditionally examined through an MCQ and written essay paper, an obstetric and pelvic mannequin examination, OSCE and long case examination. There were some changes to this as a result of the pandemic and it was essential that the assessment was standardised for all students across other maternity hospitals. Due to closure of exam halls the written essay paper was abandoned. Students completed the MCQ online. The mannequin and OSCE examination proceeded. The format of the long case examination was adapted, so that rather than taking place at a patient's bedside, students were given 15 minutes with an actress to take a history, followed by 20 minutes to prepare and 20 minutes to present and discuss with a pair of consultant examiners.

The results of a student satisfaction and feedback survey carried out for the four groups of students from September - December 2020 are reported. This survey was completed anonymously by students attending our tertiary maternity unit at the end of their four week placement. The questionnaire was distributed via email as a Google Form and students responded voluntarily within one week of module completion. Students were asked to rate several features of the programme from 1 (poor) -10 (excellent). Student responses were stored anonymously in a secure data repository and analysed using SPSS 26.0. Descriptive statistics were used to report median and standard deviation values. Median values are reported as data were skewed. The Pearson Chi-square test was used to investigate whether distributions of categorical variables differed from one another and to test for significance. A p-value of $\leq 0.05$ was considered statistically significant.

The work was part of ongoing course evaluation and was carried out in accordance with the ethical principles outlined in the Declaration of Helsinki. The anonymity of participants was guaranteed and no sensitive information was collected.

\section{Results}


Of 80 students who completed the module, 65 (81\%) completed the end-of-module survey. Satisfaction scores are displayed as median values with standard deviation. The students expressed high levels of satisfaction with clinical learning opportunities (Table 1), features of the online content (Table 2), feedback and assessment (Table 3) and support they received from their teachers, hospital staff and patients. The student feedback was very positive in relation with staff and patient engagement with students; $95 \%$ of students 'strongly agreed' or 'agreed' that hospital staff (consultants/non-consultant hospital doctors (NCHDs)/midwives) engaged with them and facilitated their learning whilst $98.5 \%$ 'strongly agreed' or 'agreed' that patients were happy to engage with them.

Table 1

Student rating of clinical allocations $(1=$ poor, $10=$ excellent)

\begin{tabular}{|lll|}
\hline 'Rate your experience in the...' & Median & SD \\
\hline Delivery Suite $(n=65)$ & 10.0 & 1.5 \\
\hline Antenatal clinics $(n=65)$ & 9.0 & 1.0 \\
\hline Hysteroscopy clinic $(n=57)$ & 9.0 & 1.5 \\
\hline Wards $(n=65)$ & 9.0 & 1.6 \\
\hline Gynaecology clinics $(n=64)$ & 8.0 & 1.9 \\
\hline Baby Clinic $(n=52)$ & 8.0 & 2.2 \\
\hline
\end{tabular}

Table 2

Student ratings of the online learning components ( $1=$ poor, $10=$ excellent)

\begin{tabular}{|lll|}
\hline 'Rate ..' & Median & SD \\
\hline 'the tutorials delivered to you through the virtual classroom' & 9.0 & 1.0 \\
\hline 'the 'Clinical Focus' Tutorials on Brightspace' $(\mathrm{n}=65)$ & 9.0 & 1.4 \\
\hline 'the live lectures given through Virtual Classroom' $(\mathrm{n}=64)$ & 8.5 & 1.1 \\
\hline 'the Study Guides'(Groups 2-4, $\mathrm{n}=46)$ & 8.5 & 1.6 \\
\hline 'the learning material available on Brightspace' $(\mathrm{n}=65)$ & 8.0 & 1.2 \\
\hline 'the pre-recorded lectures on Brightspace' $(\mathrm{n}=65)$ & 8.0 & 1.6 \\
\hline 'the podcasts posted on Brightspace' $(\mathrm{n}=65)$ & 8.0 & 2.0 \\
\hline
\end{tabular}


Table 3

Student rating of module, facilities and examination ( $1=$ poor, $10=$ excellent $)$

\begin{tabular}{|lcc|}
\hline Statement & Median & SD \\
\hline 'Rate the quality of feedback you received' $(n=65)$ & 9.0 & 1.5 \\
\hline 'Rate your overall experience of the module' $(n=65)$ & 9.0 & 0.9 \\
\hline 'Rate the hospital facilities available to you' $(n=65)$ & 9.0 & 1.7 \\
\hline 'Rate how well you think the module prepared you for the exam' $(n=65)$ & 9.0 & 1.3 \\
\hline 'Rate the exam format' $(n=65)$ & 9.0 & 1.5 \\
\hline
\end{tabular}

Most students did not feel like they missed out by being at home for tutorials which they joined virtually (Table 4). However, we noted a difference between the initial student groups (1 and 2) and final two student groups ( 3 and 4$)$. Fewer students felt they missed out by being at home in the final two groups compared with the initial two groups ( $p$-value 0.036). Table 5 displays the factors students reported as contributing to them feeling like they were missing out. There was a statistically significant difference in the number of students reporting audio $(p=0.02)$ and the lack of a webcam $(p=0.002)$ as a contributor to this between initial and final groups. The only difference to the format of tutorials and hardware available between these groups was that we obtained a new webcam for the final groups, allowing them to see the classroom/presenter during these tutorials. The median scores for students rating of 'tutorials delivered to you through the virtual classroom' was better in the groups surveyed after the webcam was introduced $(p=0.001)$.

Table 4

Student response to 'Regarding the tutorials that I joined via Virtual Classroom; I felt I missed out by being at home.'

\begin{tabular}{|llllll|}
\hline Group & $\begin{array}{l}\text { Strongly } \\
\text { Disagree }\end{array}$ & Disagree & Neutral & Agree & Strongly Agree \\
\hline All students $(n=64)$ & $10.9 \%$ & $34.4 \%$ & $26.6 \%$ & $28.1 \%$ & $0 \%$ \\
\hline Group 1\&2 $(n=34)$ & $5.8 \%$ & $32.3 \%$ & $20.5 \%$ & $41.1 \%$ & $0 \%$ \\
\hline $\begin{array}{l}\text { Group 3\&4 } \\
(n=30)\end{array}$ & $16.6 \%$ & $36.6 \%$ & $33.3 \%$ & $13.3 \%$ & $0 \%$ \\
\hline
\end{tabular}


Table 5

Student responses to 'If you felt you missed out, what factors do think contributed to this?'

\begin{tabular}{|lllllll|}
\hline Group & Audio & $\begin{array}{l}\text { Lack of } \\
\text { webcam/no } \\
\text { video }\end{array}$ & $\begin{array}{l}\text { Internet } \\
\text { connection } \\
\text { issues }\end{array}$ & $\begin{array}{l}\text { Lack of } \\
\text { interaction }\end{array}$ & Other & $\begin{array}{l}\text { Not } \\
\text { applicable }\end{array}$ \\
\hline $\begin{array}{l}\text { All responses } \\
(n=60)\end{array}$ & $20 \%$ & $21.7 \%$ & $10 \%$ & $23.3 \%$ & $11.7 \%$ & $33.3 \%$ \\
\hline $\begin{array}{l}\text { Group 1 \& } 2 \\
(n=33)\end{array}$ & $30.3 \%$ & $36.4 \%$ & $12.1 \%$ & $21.2 \%$ & $18.2 \%$ & $15.2 \%$ \\
\hline $\begin{array}{l}\text { Group 3\& } 4 \\
\text { (n=27) }\end{array}$ & $7.4 \%$ & $3.7 \%$ & $7.4 \%$ & $25.9 \%$ & $3.7 \%$ & $55.6 \%$ \\
\hline$p$-value & 0.027 & 0.002 & 0.545 & & & \\
\hline
\end{tabular}

Table 6

Student responses to 'I would like the blended home and hospital learning approach in other modules' $(n=64)$

\begin{tabular}{|llllll|}
\hline & Strongly disagree & Disagree & Neutral & Agree & Strongly agree \\
\hline Response (\%) & $1.6 \%$ & $10.9 \%$ & $18.8 \%$ & $35.9 \%$ & $32.8 \%$ \\
\hline
\end{tabular}

Almost two thirds of students (61.7\%) 'agreed' or 'strongly agreed' that they are interested in a career in obstetrics and gynaecology, and of those $88.9 \%$ reported that the rotation influenced their interest in the specialty 'strongly' or 'quite a bit'. All students attending our hospital and availing of the blended learning approach passed the Obstetrics and Gynaecology module. To our knowledge, no student tested positive for Covid-19 during their rotation and no student was required to take COVID-19 related leave.

\section{Discussion}

In this report describing the transition of the undergraduate teaching programme in obstetrics and gynaecology from the traditional hospital based interpersonal teaching methodology to a blended learning programme partly delivered online, we found high levels of satisfaction among the students and a strong interest in postgraduate specialisation. Reassuringly, there were no examination failures and no student undertaking the module was diagnosed with COVID-19.

The use of a blended learning programme (BLP), which combines face-to-face learning and e-learning has expanded rapidly, including prior to the COVID-19 pandemic and is commonly used in medical education for both undergraduate and postgraduate training. [3] Results from a meta-analysis found that blended learning appears to be more effective than or at least as effective as non-blended instruction for knowledge acquisition in health professions education. [4] Previous studies have examined the effectiveness of introducing blended learning for particular aspects of undergraduate and postgraduate 
obstetrics and gynaecology training demonstrating a positive effect [5-9], however there are no studies to our knowledge describing the transition of a full undergraduate module in obstetrics and gynaecology to a BLP.

There are a number of strengths of a blended learning programme. The increased learner and teacher flexibility is advantageous. To demonstrate the impact of this in our own programme; prior the pandemic, teaching faculty based at multiple hospitals delivered didactic synchronous lectures and students at other hospitals joined collectively through a videoconferencing system. There were approximately 15-18 hours of these per week. If a student missed the lecture, there was no way to review it. Whereas asynchronous online lectures allow students to review content in their own time and their own pace. Equally, for teaching faculty, many of whom have busy clinical roles, providing asynchronous lectures online means that they can use their limited time to facilitate interactive small group tutorials and they have greater flexibility within the schedule as they need to accommodate fewer students at a single hospital site.

The social cognitive and social constructive theory emphasise the importance of social interaction for stimulating effective learning.[10] There is greater opportunity in a BLP for student-teacher interaction as students can come to class with background knowledge, leaving more time for problem based learning and for the implementation of a flipped classroom approach. [11] For the majority of our tutorial sessions, students were aware of what topics were going to be covered, and were advised at the beginning of the module that asynchronous lectures on tutorial topics should be reviewed prior to class time however we did not measure student engagement with this. There are concerns that by implementing a flipped classroom approach students will not complete the online material.[12, 13] Studies suggest that the effectiveness of a BLP depends on the learner characteristics and their ability to self-regulate their own learning. [14, 15] Implementing a flipped classroom or problem based learning approach also means teaching staff have to make adaptations to their teaching with their roles changing from giving information to facilitating and enabling students. [16] Teaching faculty involved in our BLP commented on increased interaction during class, getting to know the students better and increased enjoyment, however further research is needed to evaluate teacher satisfaction with the BLP.

Challenges and disadvantages also exist, some of which are temporary and many can be resolved with adequate resourcing. There is an increase in workload initially, associated with the transition phase, in order to develop and organise asynchronous online learning materials. There is also a greater technology hardware and skills requirement for staff and students requiring financial resourcing and training. Interestingly, our findings suggest that improved technological hardware seemed to improve student experience of joining tutorials virtually. The addition a webcam for Group 3 and 4, allowing students to see the classroom and teacher, appeared to result in fewer students feeling like they were missing out and may have improved the audio experience. (Table 5) Although the addition of the webcam was the only identifiable difference between the initial and final groups, it is possible that greater teacher comfort with the technology and new format could have improved student experience. Students require a suitable 
location to complete online learning. This was perhaps exacerbated by the closure of university study facilities and public libraries during the pandemic.

Online learners with a greater sense of community feel less isolated and have greater levels of satisfaction with their academic programmes. [17] Therefore it is important that opportunities for interaction are available for students undertaking asynchronous online learning. During our programme, students joined tutorials in hospital virtually, providing opportunity for interaction with teachers and students. This daily interaction with tutors and other students may have fostered a sense of belonging and connectedness.

Finally, clinical experience can be unpredictable and learning is often opportunistic. There is a risk that by students spending fewer days on the clinical site, they may not get the experiences that they require during the module. Therefore, it is our opinion that a BLP for clinical modules requires flexibility to increase specific clinical assignments if required.

Interestingly, $68.7 \%$ of students 'agreed' or 'strongly agreed' that they would like a blended learning programme in other modules. The implementation of a flipped classroom approach for gynaecology oncology topics within an obstetrics and gynaecology programme has been discussed. Student satisfaction with the approach was very high and students advocated for this method to be expanded to other parts of their curriculum. [9] The high level of interest in Obstetrics and Gynaecology as a future career amongst our students was particularly interesting and whether the high levels of satisfaction with the BLP could have contributed to this is a potential area for further study.

\section{Conclusions}

This paper describes the transition of our programme from a traditional to blended learning approach. This transition was one of the most radical changes in the undergraduate obstetrics and gynaecology module implemented at very short notice with no additional resourcing. Although challenges existed and this was very much a pilot project, the necessity to change the way we teach has revealed new opportunities, particularly the utilisation of online learning resources. Outcomes and students satisfaction scores suggest that the blended learning approach is an effective way to support teaching and learning for undergraduates in Obstetrics and Gynaecology and could have the potential to change the way future medical education is delivered.

\section{Declarations}

Funding: No funds, grants, or other support was received.

Conflicts of interest/Competing interests: The authors declare that they have no conflict of interest.

Ethics approval: As this was an anonymised survey of medical students who replied voluntarily at the end of the module we did not submit to the research ethics committee, particularly as their feedback was 
informing the development of our teaching programme. The work was carried out in accordance with the ethical principles outlined in the Declaration of Helsinki.

Consent to participate: This study was conducted from anonymised data obtained as part of ongoing course evaluation and student responses were submitted on a voluntary basis.

Consent for publication: Not applicable, no personally identifiable data were included.

Availability of data and material: The data that support the findings of this study are available from the authors upon reasonable request. Data are not publicly available.

\section{References}

1. Organisation WH. (2020) Rolling updates on coronavirus disease (COVID-19). In: 11th March. https://www.who.int/emergencies/diseases/novel-coronavirus-2019/events-as-they-happen.

2. National Women and Infants Health Programme. (2018) Irish Maternity Indicator System National Report 2017.

3. Vallee A, Blacher J, Cariou A, Sorbets E. (2020) Blended learning compared to traditional learning in medical education: Systematic review and meta-analysis. J. Med. Internet Res. 22.

4. Liu Q, Peng W, Zhang F, et al (2016) The effectiveness of blended learning in health professions: Systematic review and meta-analysis. J Med Internet Res 18:. https://doi.org/10.2196/jmir.4807.

5. Ali-Masri $\mathrm{H}$, Hassan S, Fosse $\mathrm{E}$, et al. Impact of electronic and blended learning programs for manual perineal support on incidence of obstetric anal sphincter injuries: a prospective interventional study. BMC Med Educ. 2018;18:258. https://doi.org/10.1186/s12909-018-1363-3.

6. Taylor FA, Nelson E, Delfino K, Han H. (2015) A Blended Approach to Learning in an Obstetrics and Gynecology Residency Program: Proof of Concept. J Med Educ Curric Dev 2:JMECD.S32063. https://doi.org/10.4137/JMECD.S32063.

7. Sampson K, Srinivasan S, Arynova B, Ahmed S. "Who Wants to Be an Ob/Gyne?" The Role of Blended Learning and Gaming for the Obstetrics and Gynecology Student: A Randomized Trial. Obstet Gynecol. 2016;128:41S-41S. https://doi.org/10.1097/01.AOG.0000502667.71777.11.

8. Ghareeb A, Han H, Delfino K, Taylor F. (2016) Blended Learning in Obstetrics and Gynecology Resident Education: Impact on Resident Clinical Performance. J Med Educ Curric Dev 3:JMECD.S40598. https://doi.org/10.4137/jmecd.s40598.

9. Morgan H, Mclean K, Chapman C, et al. The flipped classroom for medical students. Clin Teach. 2015;12:155-60. https://doi.org/10.1111/tct.12328.

10. Torre D, Durning SJ. Social cognitive theory: thinking and learning in social settings. In: Researching Medical Education. Chichester: John Wiley \& Sons, Ltd; 2015. pp. 105-16.

11. McLaughlin JE, Roth MT, Glatt DM, et al. The flipped classroom: A course redesign to foster learning and engagement in a health professions school. Acad Med. 2014;89:236-43. 
https://doi.org/10.1097/ACM.0000000000000086.

12. Childs S, Blenkinsopp E, Hall A, Walton G. Effective e-learning for health professionals and studentsbarriers and their solutions. A systematic review of the literature--findings from the HeXL project. Health Info Libr J. 2005;22(Suppl 2):20-32.

13. Boyle J, Quail N, Loo XY, Linn A. Flipping the classroom: is it worth the bother? Clin. Teach. 2017;14:137-8.

14. Barnard L, Lan WY, To YM, et al. Measuring self-regulation in online and blended learning environments. Internet High Educ. 2009;12:1-6. https://doi.org/10.1016/j.iheduc.2008.10.005.

15. Van Laer S, Elen J. In search of attributes that support self-regulation in blended learning environments. Educ Inf Technol. 2017;22:1395-454. https://doi.org/10.1007/s10639-016-9505-x.

16. Sharma N, Lau CS, Doherty I, Harbutt D. How flipped the medical classroom. Med Teach. 2015;37:327-30. https://doi.org/10.3109/0142159X.2014.923821.

17. Rovai AP. Sense of community, perceived cognitive learning, and persistence in asynchronous learning networks. Internet High Educ. 2002;5:319-32. https://doi.org/10.1016/S10967516(02)00130-6.

\section{Supplementary Files}

This is a list of supplementary files associated with this preprint. Click to download.

- COIBlendedLearningETuthill.pdf 